\title{
Heat Transfer Simulations of Sinusoidal Filter
}

\author{
Jan Koř́nek ${ }^{1)}$, Jaroslav Novák ${ }^{2)}$ and Jan Chyský ${ }^{3)}$ \\ 1) Jan Perner Transport Faculty, University of Pardubice, Czech Republic, e-mail: korinek.j@gmail.com \\ 2) Jan Perner Transport Faculty, University of Pardubice, Czech Republic, e-mail: jaroslav.novak@upce.cz \\ ${ }^{3)}$ Faculty of Mechanical Engineering, CTU in Prague, Czech Republic, e-mail: jan.chysky@cvut.cz
}

\begin{abstract}
This article covers various types of heat transfer simulations of a sinusoidal filter. First part is focused mainly on natural convection case including a detailed geometry thermal model of the sinusoidal filter considering air-flow in surroundings. Further, a comparison of the simplified and detailed geometries and their influences upon the final temperature field is presented. For a selected case of natural convection, comparison of two identical geometries in Ansys Fluent and StarCCM+ is showed. In the last part of this paper, results for the heat transfer simulation of the sinusoidal filter in a distributor case with active cooling are presented.
\end{abstract}

Keywords - choke, sinusoidal filter, ANSYS, STAR-CCM+, heat transfer, CFD, magnetism, natural convection, turbulence, cooling.

With an ever increasing number of applications of power converters that work with the pulse width modulation implemented by fast switching transistors, the importance of quality shielding of these devices also increases. Transmitters with the pulse width modulation are used in frequency-controlled drives, photovoltaic power engineering, electromobility charging systems, power engineering and other areas. Results of the high du / dt values and the harmonic distortion of the currents are the parasitic capacitance currents, interconnections between the parasitic mutual inductances, electromagnetic radiation with the impact on the interference of the surrounding electronic devices, and their decrease of efficiency in case of frequency-controlled electric motors [1].

The basic elements for the interference suppression of the frequency converters working with the pulse width modulation are solved on the basis of passive components - chokes and capacitors. Interference suppressions increase the demands of the device on volume, weight, cost and, in the case of chokes that are usually wound on the ferromagnetic core, are an unpleasant feature of heat losses. Thermal losses of the interference suppression chokes arise both in the winding and in the iron magnetic circuit. The magnitude of the heat losses of the choke depends on the design parameters (geometrical arrangement, materials used), current flow, voltage drop and harmonic composition of current and voltage. For example, sinusoidal filters with a rated current of hundreds of amps make a loss of up to hundreds of watts. Surface temperatures of the chokes can reach up to $70^{\circ} \mathrm{C}$ or more [1].

One of the most demanding stages of the design is the calculation of the thermal properties and warming of the interference suppression chokes. A highly sophisticated approach provides finite element method. These procedures are demanding both from the point of view of the correct system and its parameters, as well as from the point of view of the demands of computational power and calculation time. These procedures are generally worthwhile when it is unrealistic to perform verification experiments on finished products with the structure gradual correction, or if it is a large production series of interference components or to verify simpler computational methods [1].

\section{THERMAL MODELLING OF SINUSOIDAL FILTER}

This article presents a method of thermal modeling applied to a sinusoidal LC filter manufactured by Skybergtech s.r.o. with a rated current of $16 \mathrm{~A}$, rated voltage of $3 \times 400 \mathrm{~V}$, which is preferably designed to interfere with the output of the frequency inverter for the induction motor. The sinusoidal filter is a very effective suppressing device that largely eliminates the influence of the pulse width modulation, on its output it is almost sinusoidal shape of voltage and current.

In the very first stage of the research it was focused on modeling of physical case considering the sinusoidal filter under load and related heat transfer during natural convection. It was an intention to create a undemanding model with simplified geometry of the sinusoidal filter. Heat transfer from the device into surroundings was considered by several calculated heat transfer coefficients, each related to a specific surface section. The resulting thermal field was subjected to validation measurement of the surface temperatures on physical piece of the sinusoidal filter conducted by thermocouples and by thermovision. Paper [2] deals in depth with the thermal modeling of case described above and with validating methodology as well. Based on conclusions in paper [2] following research activities are proceeded to create a more sophisticated and optimized thermal model.

\section{COMPARISON OF THERMAL ANALYSIS - SIMPLIFIED VS. DETAILED GEOMETRY}

\section{1) Geometry, boundary conditions and settings:}

Two thermal analyses of the sinusoidal filter each with different approach were performed.

First analysis considers a geometrically simplified CAD data of the sinusoidal filter choke model with characteristic dimensions based on the product specification. Simulation is time dependent and therefore its settings, mesh creation, definition of boundary conditions and final post processing were conducted with the Ansys Transient Thermal software.

In case of the second analysis, major difference is obtained by geometry that is more complex. Into the CAD 
model additional parts like capacitors, screws, mountings and capacitor wires are included. Coils, mounting brackets and bobbins are remodelled into significant increase of details. To cover conduction effect into surroundings, power cables and wooden desk below sinusoidal filter are added. Another difference can be found in approach how heat transfer from filter into surroundings is calculated. First simplified analysis uses manual computation of the heat transfer coefficient and set up as one of boundary conditions, however in the second variant it is numerically calculated by software as a one of the results. Therefore, the temperature distribution from the second variant is solved by the Ansys Fluent module.

Due to added capacitor parts, we can use term "Sinusoidal Filter" compared to "Sinusoidal Filter Choke" in first two cases.

Both analyses consider the monolithic core CAD model keeping the characteristic dimensions according to Waasner DIN EN 10106, EI 175/175 with the material characteristic M330-50A. The winding represents a monolithic solid. Its characteristic dimensions are related to the sinusoidal filter product specification. To the winding frame, the material characteristics for Pocan B4239 are assigned. See full list of the material properties assigned into each component in Tab.1.

TABLE I.

MATERIAL PROPERTIES

\begin{tabular}{|c|c|c|c|}
\hline Part & $\begin{array}{c}\text { Density } \\
\left(\mathbf{k g} \cdot \mathbf{m}^{-\mathbf{3}}\right)\end{array}$ & $\begin{array}{c}\text { Specific Heat } \\
\left(\mathbf{J} \cdot \mathbf{k g}^{-\mathbf{1}} \mathbf{K}^{-\mathbf{1}} \mathbf{~}\right.\end{array}$ & $\begin{array}{c}\text { Thermal } \\
\text { Conductivity } \\
\left(\mathbf{W} \cdot \mathbf{m}^{-1} \cdot \mathbf{K}^{-\mathbf{1}}\right)\end{array}$ \\
\hline Core & 7850 & 490 & 60,5 \\
\hline Textit & 1560 & 1180 & 0,39 \\
\hline Bobbin & 1500 & 1040 & 0,25 \\
\hline Coil & 8933 & 386 & $400-$ dir. X \\
\hline Mountings & 8933 & 386 & - dir. Y,Z \\
\hline Capacitor & 1005 & 1765 & 0,19 \\
\hline Screw insulation & 1500 & 1040 & 0,25 \\
\hline Wire insulation & 1420 & 1000 & 0,16 \\
\hline Aluminium parts & 2719 & 871 & 202,4 \\
\hline Steel parts & 8030 & 502,5 & 16,3 \\
\hline Copper parts & 8978 & 381 & 387,6 \\
\hline Wooden desk & 700 & 2310 & 0,173 \\
\hline
\end{tabular}

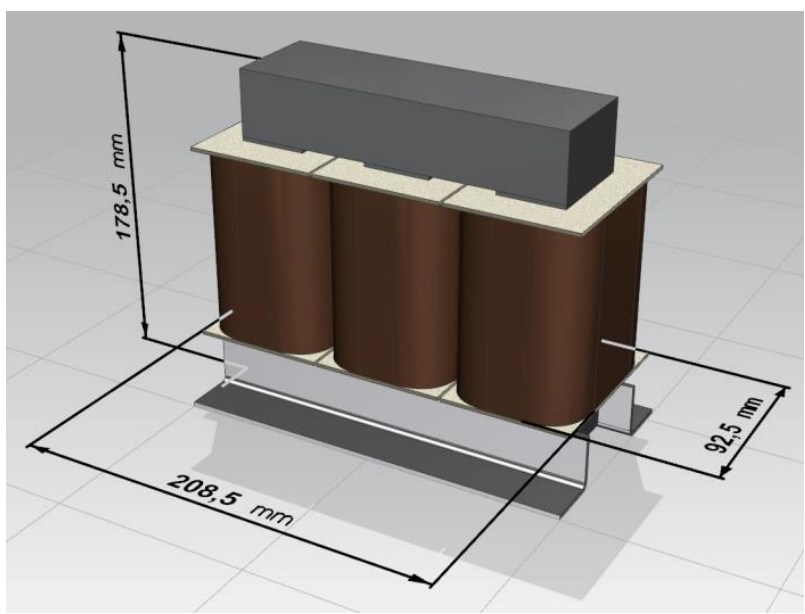

Fig. 1. Simplified CAD model of sinusoidal filter choke. [2]

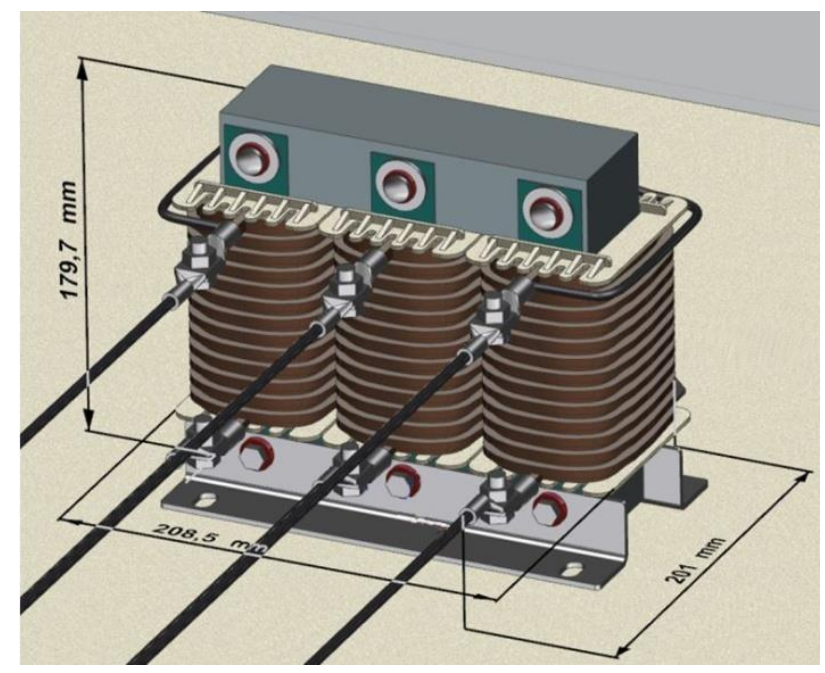

Fig. 2. Detailed CAD model of sinusoidal filter - front.

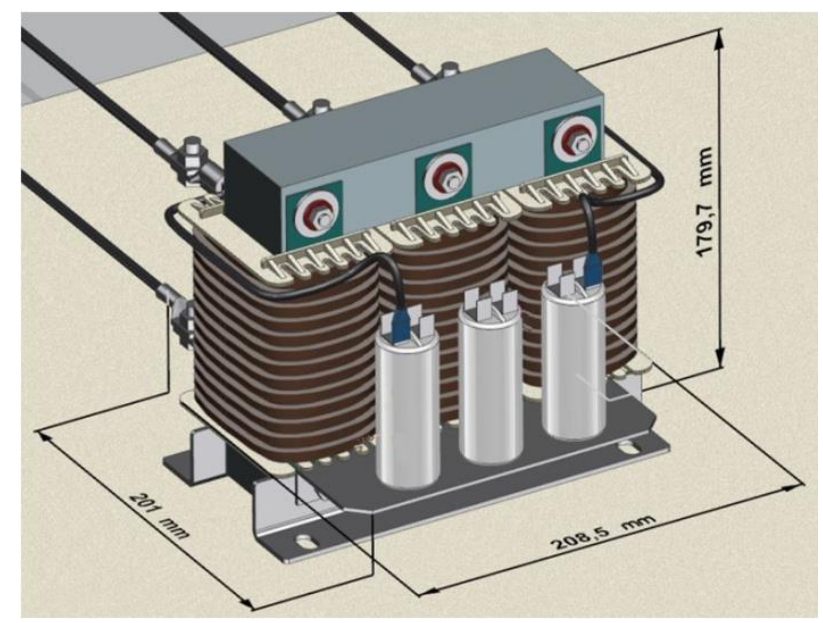

Fig. 3. Detailed CAD model of sinusoidal filter - rear.

Mesh of the simplified variant use no symmetry resemblance and consist approximately $85 \%$ of the hexahedral type elements. Detailed geometry contains surroundings computational domain of air $(5 \mathrm{~m} \times 5 \mathrm{~m} \times 6 \mathrm{~m})$. Symmetry resemblance in ZY plain was utilized to decrease the solution time. Most of the elements are of polyhedral type. 
Although complete wiring description and parameters of the sinusoidal filter are already presented in paper [2], it is suitable to repeatedly mention some parameters, which are linked to boundary condition of the simulation. Frequency converter built on his output an associated pulse width modulation voltage PWM pulsing with $4 \mathrm{kHz}$ frequency. For testing purposes the sinusoidal filter was overloaded by 1.5 times of the nominal alternate current. Values of power losses were calculated by approach published in [3] [9] and provided by the manufacturer. Based on that, the power losses of the core were $17.2 \mathrm{~W} /$ winding. The losses of the stand- alone winding are $15.9 \mathrm{~W}$. The capacitors losses are $1 \mathrm{~W} /$ capacitor. The environment temperature of the air was $15^{\circ} \mathrm{C}$. For a simplified case of simulation it was calculated 13 heat transfer coefficients $h$ as the boundary conditions in the range from 5 to $30 \mathrm{~W} \cdot \mathrm{m}^{-2} \cdot \mathrm{K}^{-1}$ according Eq. (1),

$$
h=N u \cdot k / L
$$

where $N u$ expressing Nusselt number, $k$ is thermal conductivity and $L$ is characteristic dimension.

Detailed geometry case in the Ansys Fluent is solved by a pressure-based solver with consideration of gravity influence as transient solution. The computational model includes energy equation. This equation represents energy transfer due to conduction, species diffusion, and viscous dissipation, and volumetric heat sources. In the solid regions, the energy transport equation has the following form - (2) [7],

$$
\frac{\partial}{\partial t}(\rho h)+\nabla \cdot(\vec{v} \rho h)=\nabla \cdot(k \nabla \mathrm{T})+S_{h}
$$

where $t$ expressing time, $\rho$ density, $h$ sensible enthalpy, $\vec{v}$ velocity, $T$ temperature and $S_{h}$ is volumetric source.

2) Resulting temperatures based on measurements and Ansys simulations:

A temperature measurement of the sinusoidal filter has taken place using thermocouples and thermovision. Fluke ${ }^{\circledR}$ Ti125 was used for screening of the infrared radiation generated by the sinusoidal filter surface.

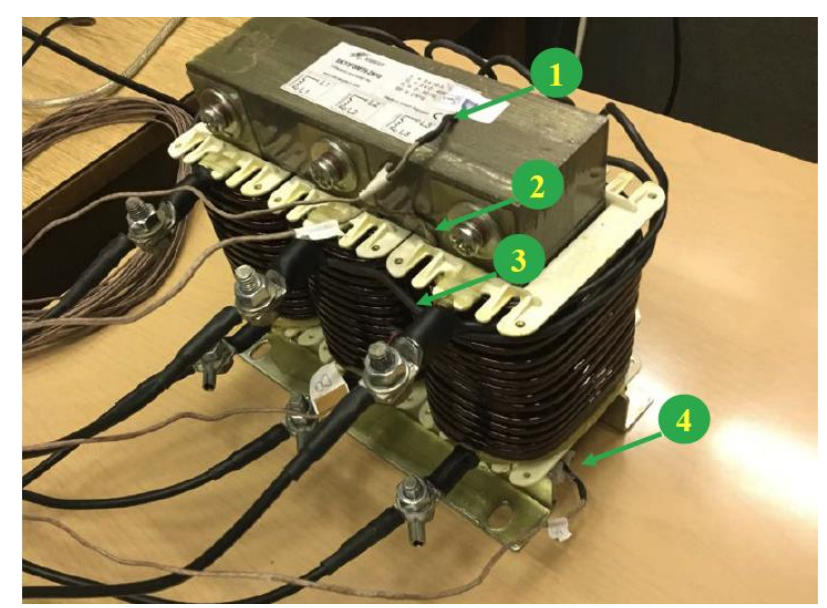

Fig. 4. Thermocouples positioning [2]

1 - upper core surface

2 - gap between core and winding frame

3 - gap between windings

4 - bottoms core surface

Warming characteristic on the physical piece was measured for 5 hours $(18000 \mathrm{~s})$. Due to this fact all presented results and characteristics are subtracted for this timeframe.

Comparison of the thermovision surface screen and simplified variant temperature field shows that in areas of the side windings the differences can reach up to $7^{\circ} \mathrm{C}$, which can be seen in Fig. 5.
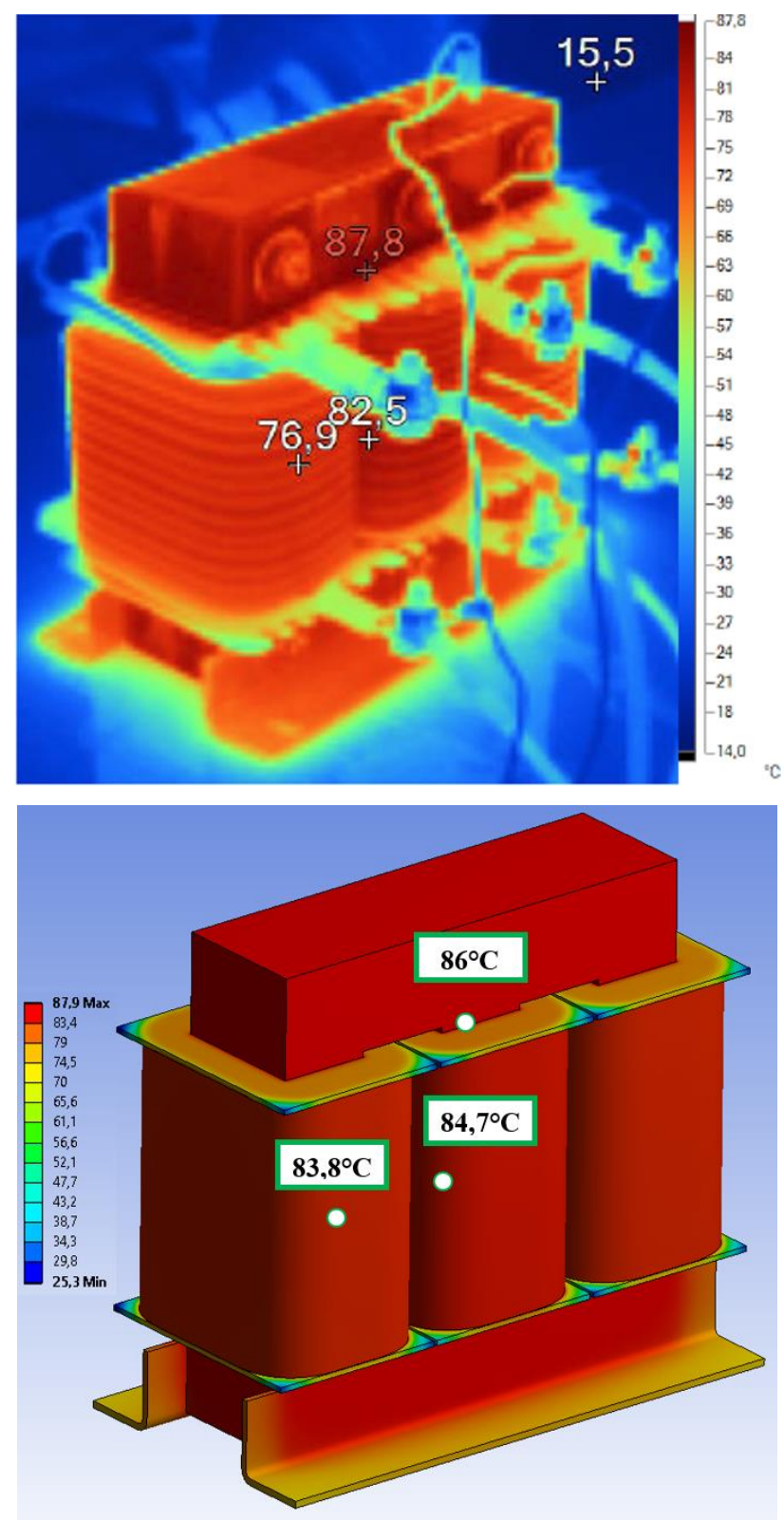

Fig. 5. Temperature fields -5 hours load [2]. upper - thermovision screen lower - simplified variant

The detailed variant presented in Fig.6 on the other hand reached overall higher temperatures. In this case, differences are in the range from $3.2^{\circ} \mathrm{C}$ up to $5.4{ }^{\circ} \mathrm{C}$ in comparison with thermovision. 

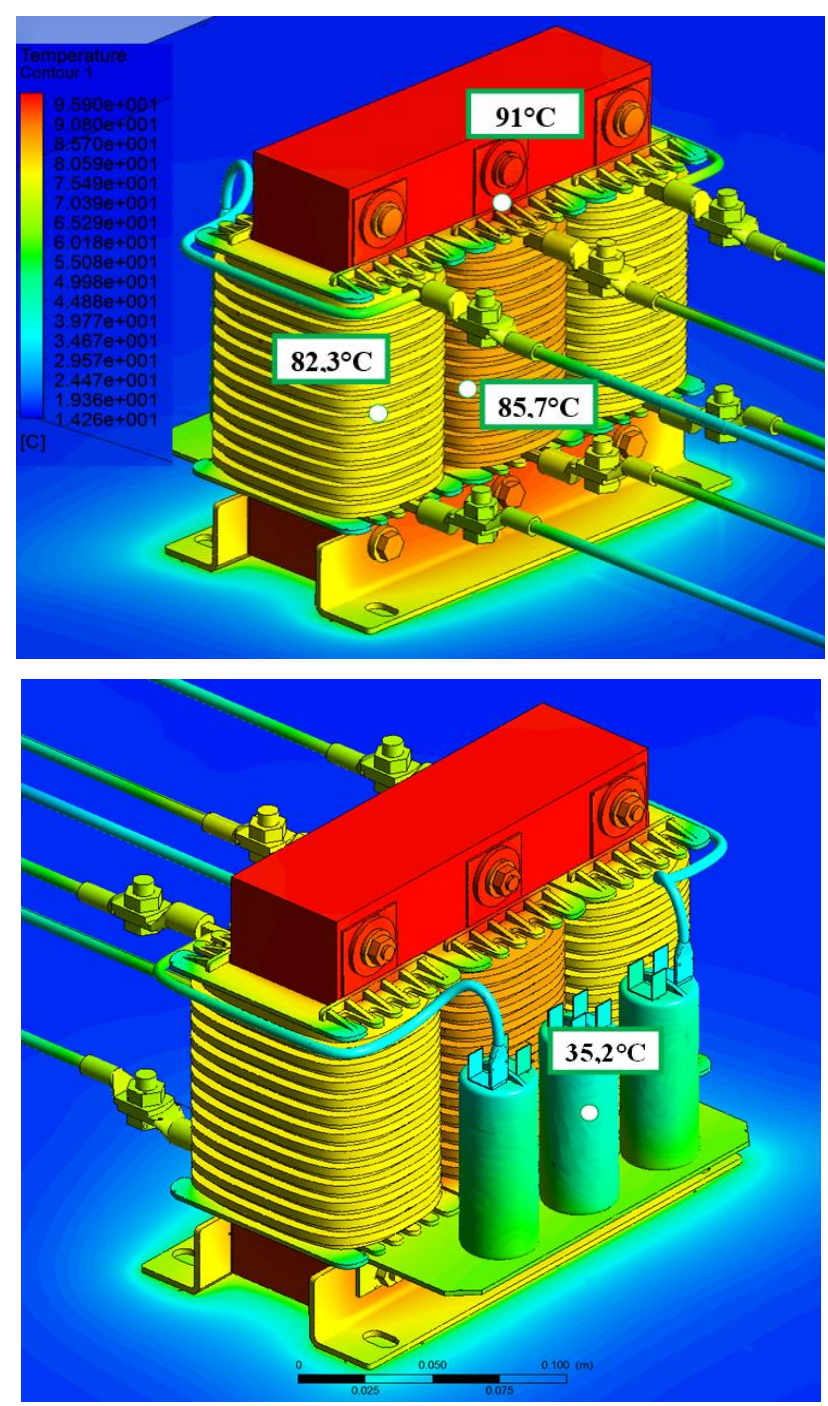

Fig. 6. Temperature fields -5 hours load [2]. upper - detailed variant -front lower - detailed variant -rear

From the previous research published in [2] it is known that highest temperature across the whole sinusoidal filter based on results for simplified geometry simulated in the Ansys Transient Thermal is in the area of central winding in centre of the core. Fig. 7 shows comparison of the achieved global maximum temperatures between the simplified analysis and detailed analysis simulated in the Ansys Fluent. For the simplified case, after 5 hours load the highest temperature reached $90.4{ }^{\circ} \mathrm{C}$. The detailed variant at the same time reached $98{ }^{\circ} \mathrm{C}$. It is possible to notice that according to the settling characteristic of temperature, the detailed variant did not reach steady state. This state was reached after 12.6 hours from beginning.

The diagram in Fig. 8 describes the temperature values in four measuring points performed by thermocouples. In time of 5 hours under load temperatures from both variants and thermovision were determined and added for comparison. The detailed variant reached the highest temperatures due to calculation of the heat transfer coefficient in each element.

If we consider the same power losses in both simulation variants, factors, which influence the final temperature values most significantly are mesh density close to the surface of the sinusoidal filter, value of the time step and inner iteration of the time step. The impact of the mentioned parameters can be in range of units of degrees Celsius. For current simulation in Fluent, the applied step size was up to $1200 \mathrm{~s}$ and the time, required to simulate results is approximately threefold of the required time of a simplified case simulation.

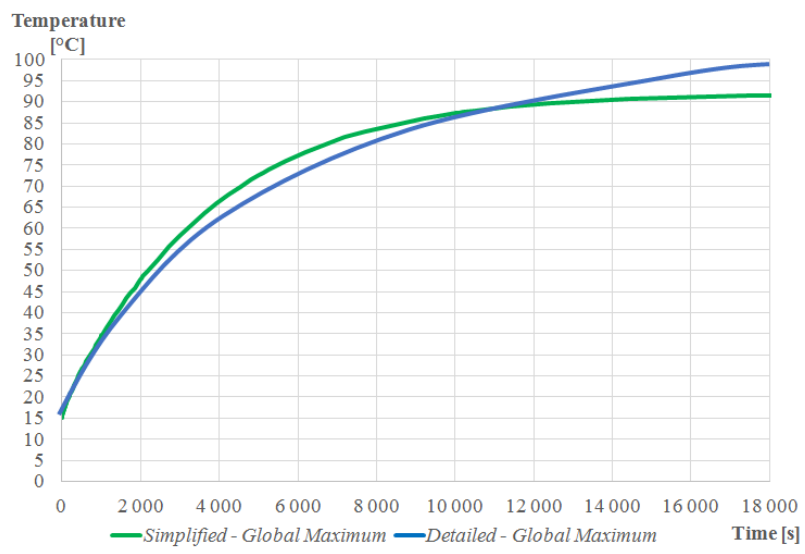

Fig. 7. Settling of temperatures -5 hours load.

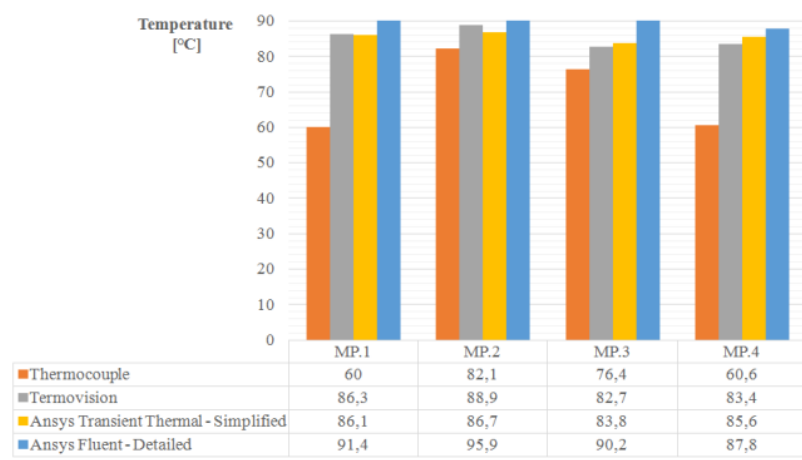

Fig. 8. Comparison of temperatures from points 1-4. 5 hours load.

\section{COMPARISON OF THERMAL ANALYSIS IN ANSYS FLUENT AND STARCCM+}

The Ansys and its engineering simulation tools are well known through academia and industry. Therefore, it is highly likely when development task needs to be solved, the related person will come into contact with those tools. To solve the heat transfer problems, it is possible to use other tools for numerical simulations, which are available on the market. One of them is for example STAR-CCM+. The intention was to simulate exactly the same natural convection case in both software and compare them from various point of views related to results accuracy, hardware and time requirements and user friendliness. The cover of all of those areas is out of scope of this paper, therefore the comparison of the resulting temperature fields is presented below.

\section{1) Geometry, boundary conditions and settings:}

A simplified geometry of the sinusoidal filter presented in Fig. 1, was selected as a test case, with regard to surrounding air. Boundary conditions (power losses, air temperature) and material properties used in both software were the same as the in previous chapter of this paper.

Whole case is simulated as transient and air-flow considered as laminar. Solver settings contain coupled energy, Boussinesq model and gravity [8]. 
Overall geometry is meshed by polyhedrals. In total, the STAR-CCM+ mesh contains approximately $5 \%$ less elements than the Ansys Fluent mesh with acceptable quality for simulation. Although the STAR-CCM+ mesh contains slightly less elements, whole simulation of double precision solution take $27 \%$ more time than solution in the Ansys Fluent.

2) Resulting temperatures based on STAR-CCM+ and Ansys simulations:

Final temperature field after a steady state is shown in Fig. 9. In general, temperatures based on the results from the STAR-CCM+ are from $2{ }^{\circ} \mathrm{C}$ up to $5{ }^{\circ} \mathrm{C}$ lower than from the Ansys Fluent. It is also possible to see the difference in concentration of the highest temperatures at the sinusoidal filter geometry. According to the STAR-CCM+, the central winding is part where the maximum temperature of the whole device is located. In case of the Ansys Fluent, this area includes the central winding and upper part of the core.
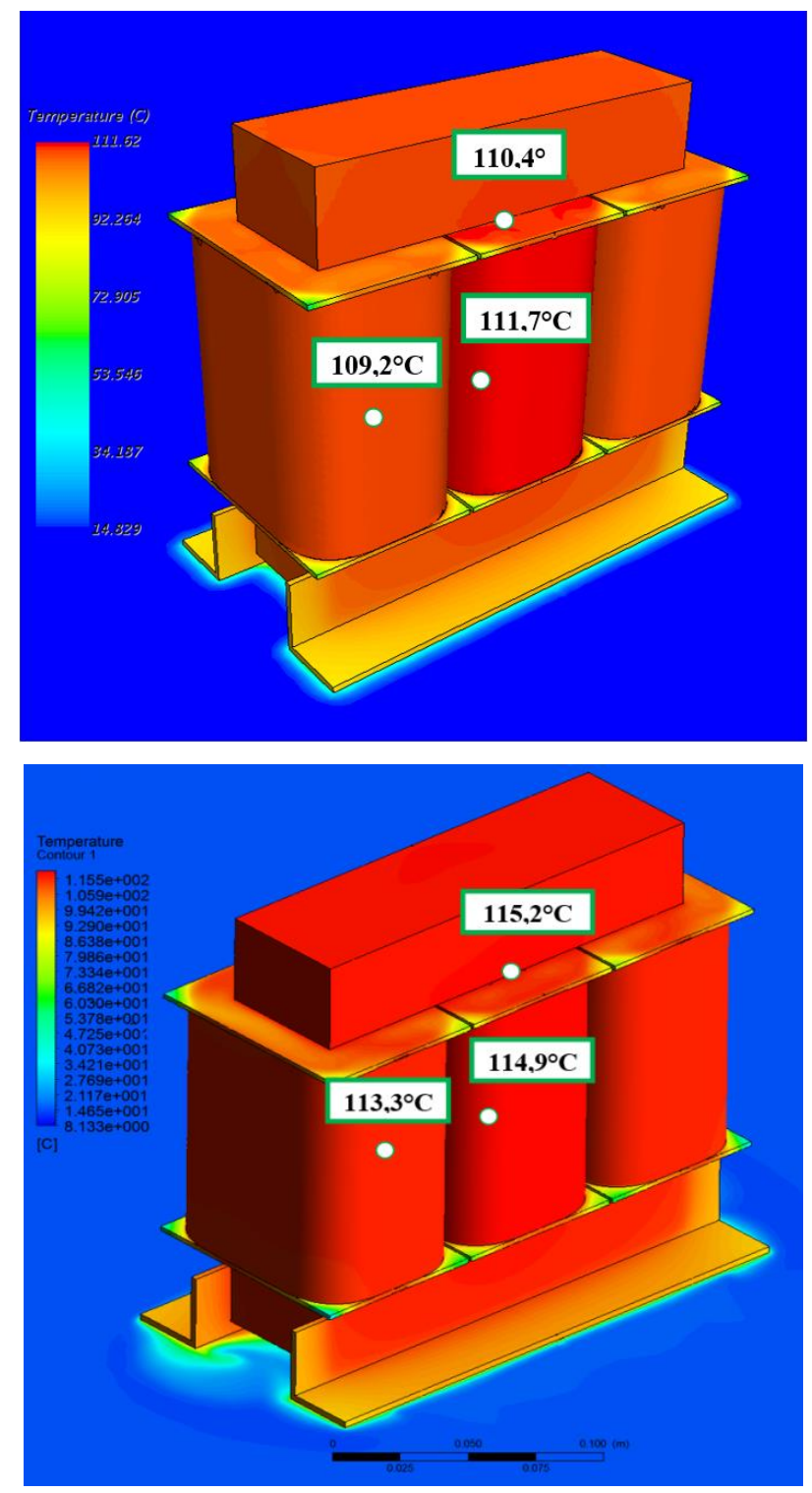

Fig. 9. Temperature fields - steady state. upper - STAR-CCM+ lower - Ansys Fluent
The time-dependent temperature settling characteristic represents Fig. 10. Characteristic is related to the maximum achieved temperature in the sinusoidal filter geometry. Based on the STAR-CCM+, the maximum temperature is settled at $112{ }^{\circ} \mathrm{C}$ in time of 10.5 hours (approx. $37000 \mathrm{~s}$ ). Compared to the Ansys Fluent simulation, it results in the settling time of 12.5 hours $(45000 \mathrm{~s})$ at the maximum global temperature $116^{\circ} \mathrm{C}$.

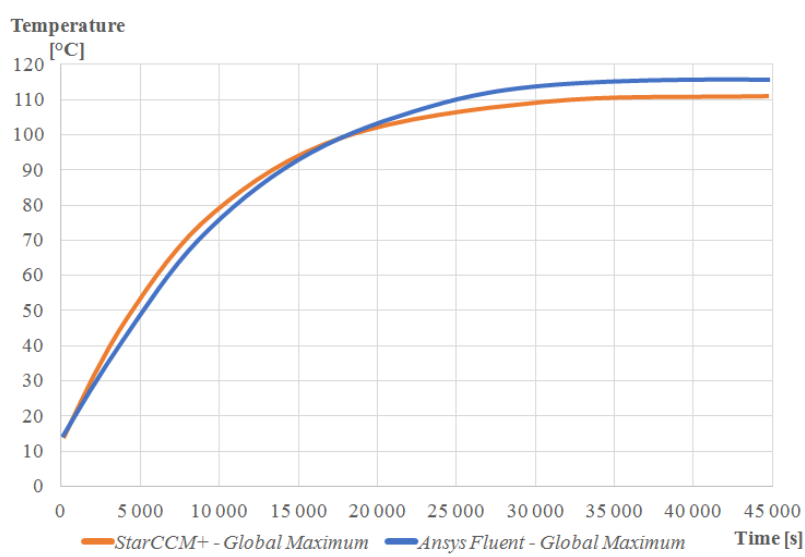

Fig. 10. Settling of temperatures - steady state.

The diagram in Fig. 11 shows comparison of the temperature values located in the measuring point described in [2]. In all points, the STAR-CCM+ reached lower temperatures in comparison with Ansys.

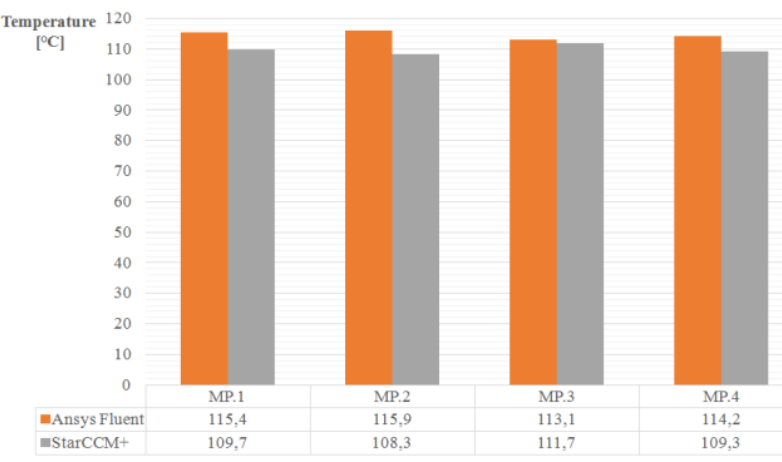

Fig. 11. Comparison of temperatures from points 1-4. Steady state.

\section{THERMAL ANALYSIS OF SINUSOIDAL FILTER WITH ACTIVE COOLING}

While the natural convection case published in the previous chapters was performed mainly to gain knowledge about interactions between inputs and resulting thermal outputs in simulation concept, outer conditions were not typical for common usage of the sinusoidal filter. Under standard conditions, most of them are located in various distributors with certain system of active cooling. Therefore, after completion of the natural case validation, preparation of simulation case of the sinusoidal filter with active cooling has started with consideration of the previously gained experience.

\section{1) Geometry, boundary conditions and settings:}

Whole simulation case was prepared for exactly the same sinusoidal filter SKY3FSM16-2kHz as in the previous natural convection thermal analysis. The sinusoidal filter was powered by alternating current frequency of $50 \mathrm{~Hz}$ 
with a superimposed high-frequency component resulting from switching frequency of the frequency converter. The frequency converter built on his output an associated pulse width modulation voltage PWM pulsing with $4 \mathrm{kHz}$ frequency. The sinusoidal filter was loaded with the $7 \mathrm{~A}$ current. The capacitor losses are $0.35 \mathrm{~W} /$ capacitor. The power losses value on the core was $9.65 \mathrm{~W} /$ winding and the stand-alone winding losses are $2.26 \mathrm{~W}$. The air environment temperature was $22.5^{\circ} \mathrm{C}$.

Regarding the usage of active cooling, character of the air-flow is different in comparison with the previous natural convection case. Wrapping air-flow near the sinusoidal filter surface exhibits chaotic fluctuations in space and time, therefore modeling of turbulence in the air-flow is needed. For turbulent flow pulsations of all quantities are typical. Trajectories of particles are irregular and therefore significant mixing of flow volume is created. Quantity, e.g. velocity has oscillatory character. It is possible to decompose it to the mean value by time $\tilde{u}$ and fluctuation value by time $u^{\prime}$. The actual velocity vector is according (3) [5] [6].

$$
\vec{u}=\widetilde{\vec{u}}+\vec{u}^{\prime}
$$

One of the options to model turbulence is to modify continuity and Navier-Stokes equations by (3), then it is possible to get form (4), where $\widetilde{\vec{\tau}}^{(\pi)}$ is the mean value by time of the dynamic stresses overall tensor. This consist of the mean value by time of the viscosity stresses tensor $\widetilde{\vec{\tau}}^{(t)}$ and the mean value by time of the turbulent stresses tensor $\widetilde{\vec{\tau}}^{(t)}[4][5][6]$.

$$
\begin{aligned}
& \rho \cdot \frac{D \widetilde{\vec{u}}}{D t}=-\nabla \tilde{p}+\nabla \cdot \widetilde{\overrightarrow{\vec{\tau}}}^{(T)}+\rho \cdot \vec{f} \\
& \widetilde{\overrightarrow{\vec{\tau}}}^{(T)}=\widetilde{\overrightarrow{\vec{\tau}}}+\widetilde{\vec{\tau}}^{(t)} \\
& \widetilde{\overrightarrow{\vec{\tau}}}^{(t)}=-\rho \widetilde{\vec{u}}^{\prime} \widetilde{\vec{u}}^{\prime}
\end{aligned}
$$

For validation purposes distributor case with active cooling system where sinusoidal filter was installed was build. Dimensions of the distributor are $0.6 \times 0.9 \times 1.6 \mathrm{~m}$, which is a typical size for commercial distributors on the market. It is made of aluminium sheets and aluminium profiles combination. An AC centrifugal fan located in the lower centre of the distributor provides the air distribution. Then air leaves by open ceiling wall into further surroundings. Inside, the sinusoidal filter is located on the two aluminium profiles in the middle of the distributor $0.56 \mathrm{~m}$ above the ground.

On the right side of Fig. 12, it is possible to see CAD geometry used for simulation. It contains the most detailed variant of the sinusoidal filter already used in natural convection cases with the same applied material settings as in Tab. 1. This model includes power cables and capacitors wiring as well.
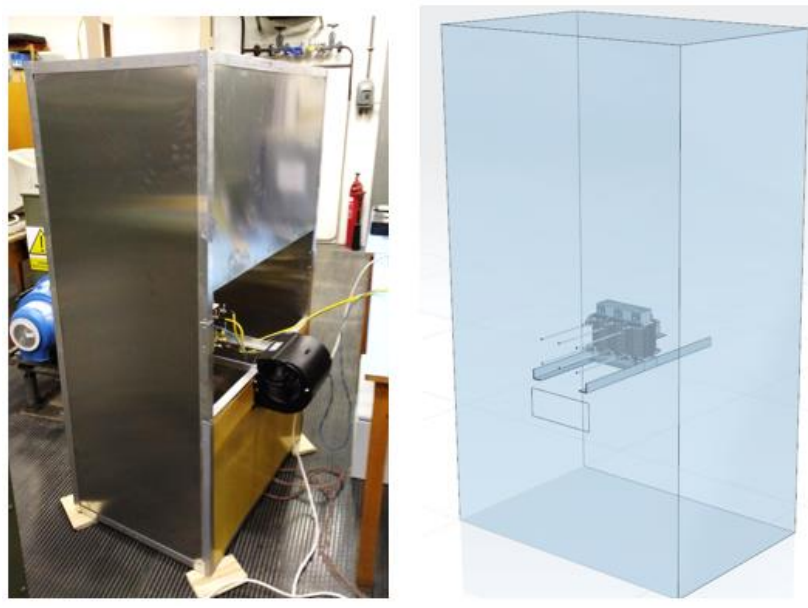

Fig. 12. Distributor setup.

left - physical distributor (temporarily opened) right - CAD model for simulation

The surface temperature field was captured by thermovision and by 8 thermocouples attached on the sinusoidal filter. Ninth thermocouple (No. 8) measured the surface temperature of the carrier aluminium L-profile below the sinusoidal filter, which was already part of the distributor.

The thermocouple No. 0 is attached to the upper surface of the core. No. 1 is inserted into a slot between core and winding frame. On the front and rear surfaces of the middle winding, thermocouples No. 2 and 3 are attached. The thermocouple No. 4 is attached to the lower surface of the core. On the surface of the middle capacitor temperature is measured by the thermocouple No. 5. No. 6 measures temperature of the capacitor holder and No. 7 is used for monitoring of the side winding temperature.

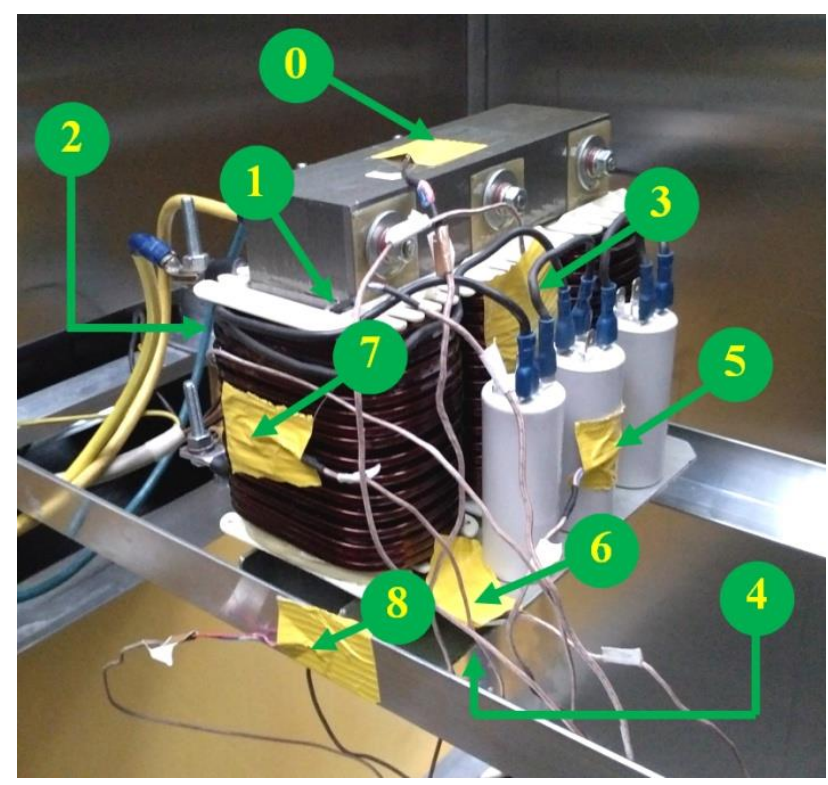

Fig. 13. Thermocouples positioning.

2) Resulting temperatures based on measurements and Ansys simulations:

The resulting temperatures were screened by the thermovision Flir i50 at the steady state for the selected airflow velocity of $5 \mathrm{~m} \cdot \mathrm{s}^{-1}$ as Fig. 14 shows. The temperature 
field from simulation provides more optimistic results than measurement by thermovision in this case. The decomposition of the temperature field visible on the frontal area is very similar for simulation and thermovision. On the upper surface of the core, the difference is up to $2{ }^{\circ} \mathrm{C}$. In case of both windings, according to thermovision, temperature reached $3.5^{\circ} \mathrm{C}$ higher values than in the simulation.
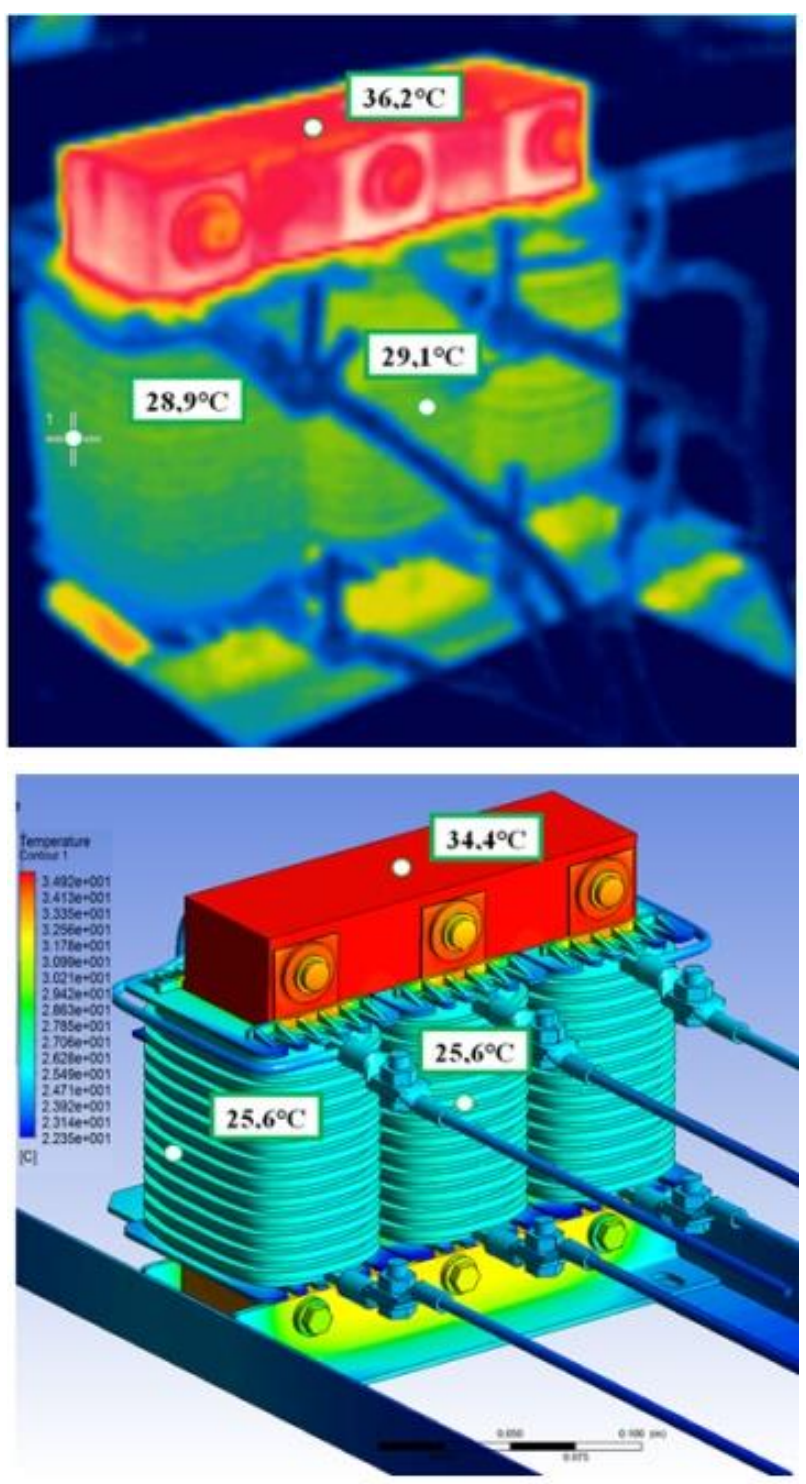

Fig. 14. Front view of temperature fields - steady state; air-flow $5 \mathrm{~m} \cdot \mathrm{s}^{-1}$ upper - thermovision screen

lower - simulation

Figure 15 depicts rear area of the sinusoidal filter in the distributor. In this area it can be focused on the capacitor temperature field and related holders. Those parts are not main generators of heat and therefore as the maximum overall temperatures are lower, mutual temperature differences for simulation and measurement are lower as well. Temperature in the monitoring point at the rear side of the central capacitor rose up to $25.2^{\circ} \mathrm{C}$ according the thermovision, which is $0.6{ }^{\circ} \mathrm{C}$ higher than in the simulation. Similar difference is in case of aluminium beam where the difference is $1.3^{\circ} \mathrm{C}$. The aluminium capacitor holder shows larger differences of the temperature field. In the measured point, temperature screened by the thermovision is $3.1^{\circ} \mathrm{C}$ higher than from the simulation. The temperature spreading character is not so smooth as in the simulation.
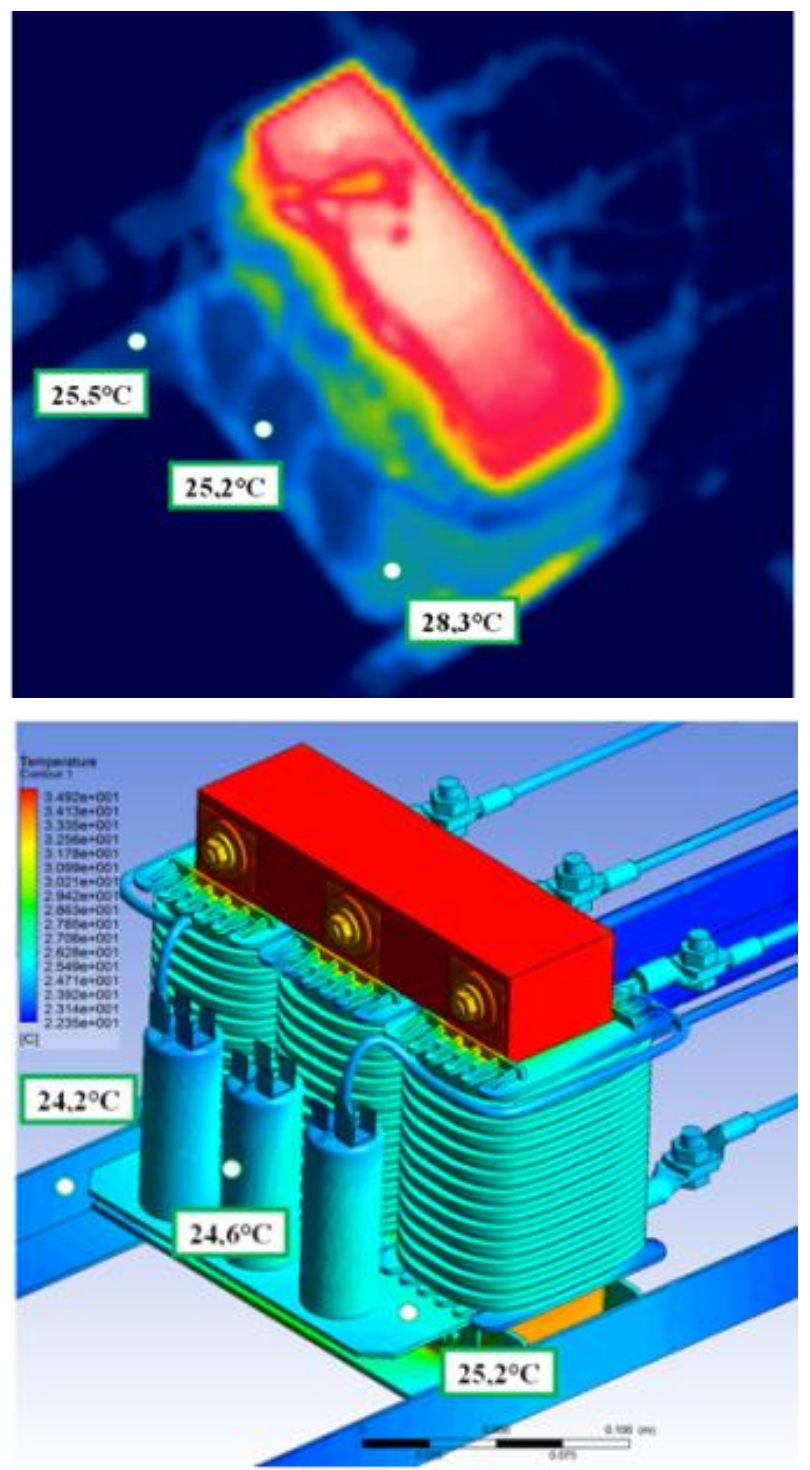

Fig. 15. Rear view of temperature fields - steady state; air-flow $5 \mathrm{~m} \cdot \mathrm{s}^{-1}$. upper - thermovision screen lower - simulation

For the selected air-flow velocity of $5 \mathrm{~m} \cdot \mathrm{s}^{-1}$, comparison of the maximum temperatures between thermovision, thermocouples and simulation was created as described in Fig. 16. As in the previous natural convection case, it is possible to see that according the thermovision measurement, resulting temperatures are higher than by the thermocouples. However, the measuring point No. 1 shows opposite behavior. This can be caused by fact that the thermocouple measures value in gap about $2 \mathrm{~mm}$ under the surface in comparison with the thermovision where gap measurement is limited by field of view.

In case of the simulation results across all measuring point, it is possible to see that the maximum temperatures are lower than from measurement tools. Exception can be seen in case of the point No. 0 where the thermocouple shows lower value. This is caused by fastening of the thermocouple in this point, which is not optimal as was found out later. 


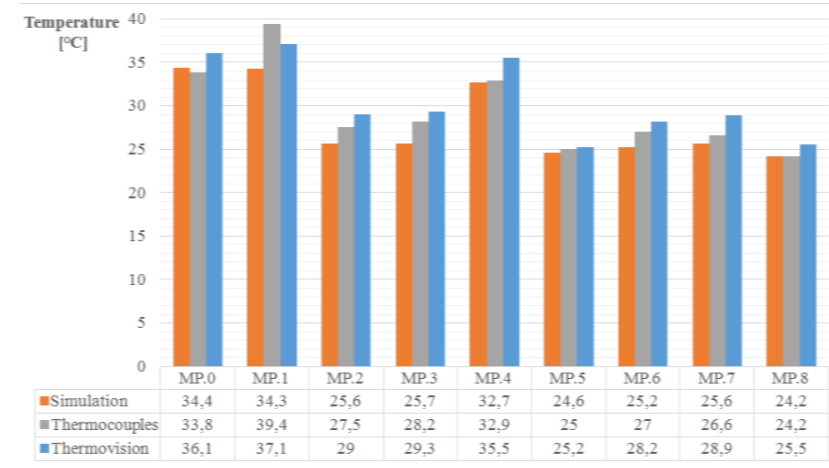

Fig. 16. Comparison of temperatures in points $1-8$ based on simulation, thermocouples and thermovision for air-flow $5 \mathrm{~m}^{\cdot} \mathrm{s}^{-1}$.

To obtain information about overall effectiveness of the cooling system, Fig. 17 shows the maximum temperatures based on results from the simulation for several air-flow velocities. As a boundary condition velocity produced on output orifice of the fan for the range from $0 \mathrm{~m}^{\cdot} \mathrm{s}^{-1}$ up to $15 \mathrm{~m} \cdot \mathrm{s}^{-1}$ was setup. It is possible to see that the temperature drop after velocity increasing has major significance between 0 and $5 \mathrm{~m} \cdot \mathrm{s}^{-1}$. At higher air-flow velocities, temperature biggest drops are up to $3.5^{\circ} \mathrm{C}$ in comparison between 5 and $15 \mathrm{~m} \cdot \mathrm{s}^{-1}$ or less in dependency on the actual measuring location.

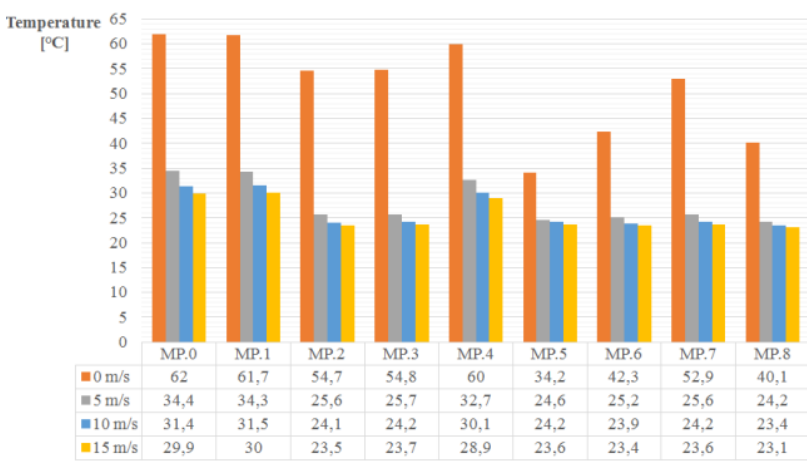

Fig. 17. Comparison of temperatures in points $1-8$ based on simulation for air-flow $0 ; 5 ; 10$ and $15 \mathrm{~m} \cdot \mathrm{s}^{-1}$.

\section{CONCLUSION}

Activities presented in this paper were mostly related to conclusions and further optimization intentions presented in [2].

Impact of detailed geometry variant upon the final decrease of overall temperatures demonstrated, that the heat transfer coefficients from surface of the sinusoidal filter into surroundings air-flow are calculated more precisely in comparison of the manual calculation and simplified variant and therefore reflect reality more closer. Potential contradiction between results from the simplified and detailed variant where the simplified method match closer the validation measurement results can be explained by relation with power losses value. The resulting temperatures from the detailed variant indicate potential to review the power losses determination method and run simulation again with new values.

The simulation variant, which contains active cooling, indicate that for the existing setup the effect of higher airflow velocities is not significant. Therefore further potential can be seen to test range of lower air-flow velocities e.g. from $0.5 \mathrm{~m} \cdot \mathrm{s}^{-1}$ up to $4 \mathrm{~m} \cdot \mathrm{s}^{-1}$.

Even if in some cases the simulated temperature field is relatively close to result from the validation measurements, it remains to clarify credibility of the power losses values. To prove general validity of the simulated models, it needs to be tested on more types of the sinusoidal filters.

\section{ACKNOWLEDGMENT}

This text was created with support of the project Studentská grantová soutěž SGSDFJP 2017001. Creation was also supported by company SKYBERGTECH s.r.o., which borrowed the sinusoidal filter and provided consultations during validation measurements. Acknowledgment belongs also to Faculty of Mechanical Engineering at CTU Prague for support.

\section{REFERENCES}

[1] KOŘÍNEK, J. a NOVÁK, J. Časopis ELEKTRO. Roč. 2017, ISSN 0322-9025. Analýza účinku geometrických charakteristik cfd simulaci na teplotni pole sinusoidalového filtru. Praha, FCC Public s.r.o., 2017.

[2] KOŘÍNEK, J. Validation of Sinusoidal Filter Choke Temperature Model. Transactions on Electrical Engineering. Praha: Ergo Nomen, o.p.s., K13114 FEE CTU IN PRAGUE, 2016. ISSN 1805-3386.

[3] NOVÁK, J., CHYSKÝ, J a KOŘÍNEK, P. Ztráty sinusoidalových filtrů pro měniče se spínacími tranzistory. Elektro. 2013, 2013(10), s. 46-49. ISSN 1210-0889.

[4] LI, N. Comparison between three different CFD software and numerical simulation of an ambulance hall. Master thesis, KTH School of Industrial Engineering and Management. Stockholm 2015

[5] KOŘíNEK, J. Písemná zpráva ke státní doktorské zkoušce. Analýza teplených pomérů $v$ odušovacích komponentách elektrických pohoni. Praha.Univerzita Pardubice, Dopravní fakulta Jana Pernera. 2016

[6] KOZUBKOVÁ, Milada, BLEJCHAŽ, Tomáš and BOJKO, Marian. Modelování přenosu tepla, hmoty a hybnosti. Ostrava : VŠB Technická univerzita Ostrava, 2011. ISBN - 978-80-248-2491-8.

[7] Ansys Fluent Theory Guide. Ansys inc. Canonsburg 2016: http://www.ansys.com

[8] STAR-CCM+ documentation. 2017 Siemens Product Lifecycle Management Software Inc. https://documentation.thesteveportal.plm.automation.siemens.com

[9] KRISHNAMOORTHY P. Electromagnetic and Heat Transfer Modeling of Microwave Heating in Domestic Ovens. Lincoln: University of Nebraska at Lincoln, May 2011. 